\title{
Hydro-Liquefaction of Tile-Like Barzas Coals in the Presence of Some Transition Metal Additives
}

\author{
Ivan Petrov ${ }^{1,}$, Konstantin Ushakov $^{2}$, Sergey Sozinov ${ }^{1}$, and Alexander Bogomolov ${ }^{2,3}$ \\ ${ }^{1}$ Federal Research Center of Coal \& Coal Chemistry, SB RAS, 650000 Kemerovo, Russia \\ ${ }^{2}$ T.F. Gorbachev Kuzbass State technical University, 650000 Kemerovo, Russia \\ ${ }^{3}$ Kutateladze Institute of Thermophysics, SB RAS, 630090 Novosibirsk, Russia
}

\begin{abstract}
Using a laboratory micro-autoclave (of $\sim 20 \mathrm{~cm}^{3}$ volume), the effects of transition metal additives $\left(\mathrm{MoO}_{3}, \mathrm{Fe}_{2} \mathrm{O}_{3}\right.$ and commercial AlCoMo catalyst) on the thermal transformations of tile-like Barzas coals (sapromixites) in a hydrogen medium at $\mathrm{T} \sim 475^{\circ} \mathrm{C}$ and $\mathrm{P} \sim 6.0-7.5 \mathrm{MPa}$ have been studied. It has been shown that catalytic additives under investigation somewhat suppress gas formation processes, facilitating the increase in $\mathrm{H} / \mathrm{C}$ atomic ratios and in the amount of alkyl-containing structures in resin-like solid products of Barzas coal hydro-liquefaction. Maximal yields of "coal liquids" (maltenes + asphaltenes) ( 35 wt.\%, daf basis) were obtained during the heat treatment of sapromixites in the presence of $\sim 1$ wt. $\% \mathrm{MoO}_{3}$.
\end{abstract}

\section{Introduction}

Hydro-liquefaction processes to produce artificial liquid fuels are rather promising ways for utilization of low-metamorphised and low-rank coals [1-4]. It was previously established [5] that among various low-metamorphosed Kuzbass coals, Barzas sapromixites are the most promising raw materials for direct hydrogenation processes to produce liquid products, since this type of solid fuels contains large amounts of hydrogen (up to 9-10 wt.\% from organic matter of coal ) and is characterized by high yields of volatile products (50-60 wt.\%). In particular, under non-isothermal conditions, sapromixites of Barzas coal field rather easily dissolve in a hydroaromatic solvent (tetralin) at already $425-450^{\circ} \mathrm{C}$ with the yield of liquefaction products (asphaltenes, resins and oils) of $\sim 60-80 \%$ per organic matter of coal [6]. Moreover, during their hydrogenation $\left(\mathrm{T} \sim 400-430^{\circ} \mathrm{C}\right.$ and $\left.\mathrm{P} \sim 7 \mathrm{MPa}\right)$ in the presence of an iron-containing catalyst and a petroleum residue (as a solvent), almost 94$97 \%$ of their organic matter is converted into gaseous and liquid products, with the yield of light liquid hydrocarbons (mainly $\mathrm{C}_{6}-\mathrm{C}_{9}$ paraffins, bp $<200^{\circ} \mathrm{C}$ ) up to $24-28 \mathrm{wt} . \%$ [7].

Thermal decomposition reactions of coals to smaller molecular fragments occurring in a hydrogen medium at high temperatures and pressures can be considered as an important stage in the process of their direct hydrogenation [4]. Therefore, a study of coal substance pyrolysis in various environments provides valuable information about basic regularities of

\footnotetext{
${ }^{*}$ Corresponding author: ipetrov@kemcity.ryu
} 
the coal conversion product formations, depending on the technological parameters of the process of solid fuel heat treatment.

In our earlier works $[8,9]$, the experiments on thermal treatment of Barzas coals in hydrogen and carbon dioxide atmospheres within the temperature range of $400-550^{\circ} \mathrm{C}$ and pressures from 7 to $11.0 \mathrm{MPa}$ have been carried out. The maximum yield of "coal liquids" (maltenes and asphaltenes) was obtained at $\mathrm{T}=475^{\circ} \mathrm{C}$ for both media. At the same time, an antibate relationship was observed between the gas yields and $\mathrm{H} / \mathrm{C}$ atomic ratios in solid tar containing products of coals heat treatment. Such behavior of Barzas coals during their thermal decompositions in various media was explained by the initial accumulation of alkyl-containing structures at $\mathrm{T}<475^{\circ} \mathrm{C}$ and their subsequent transition into the gas phase at higher thermal treatment temperatures [5, 6]. It is well known that in the presence of various transition metal-containing catalytic additives, the reactions of hydrogenation, cracking and heteroatom removal from coals during their hydro-liquefaction process are considerably intensified [1-3]. Iron- and molybdenum-based catalytic systems are amongst the most active and widely used catalysts of coal hydrogenation $[2,3]$. Therefore, in the given work, the effects of Fe- and Mo-containing additives $\left(\mathrm{MoO}_{3}, \mathrm{Fe}_{2} \mathrm{O}_{3}\right.$ and commercial AlCoMo catalyst) on the transformations of Barzas coals during their thermal treatment in a hydrogen medium have been investigated.

\section{Experimental}

\subsection{Preparation of coal samples for hydroliquefaction}

For this investigation, the most abundant, tile-like modification of Barzas coals was chosen as a raw material to study the processes of hydro-liquefaction.

Table 1. Characteristics of tiled Barzas sapromixite.

\begin{tabular}{|c|c|c|c|c|c|c|c|c|}
\hline \multicolumn{3}{|c|}{ Proximate analysis (wt \%) } & \multicolumn{5}{|c|}{ Ultimate analysis (wt \%, daf basis) } & \multirow{2}{*}{$\begin{array}{c}\mathrm{H} / \mathrm{C} \\
\text { atomic } \\
\text { ratio }\end{array}$} \\
\hline $\mathbf{W}^{\mathbf{a}}$ & $\mathbf{A}^{\mathbf{d}}$ & $\mathbf{V}^{d a f}$ & $\mathbf{C}$ & $\mathbf{H}$ & $\mathbf{N}$ & $\mathbf{S}$ & $\begin{array}{c}O(b y \\
\text { difference) }\end{array}$ & \\
\hline 1.7 & 25.8 & 50.1 & 84.78 & 8.91 & 0.56 & 1.24 & 4.51 & 1.26 \\
\hline
\end{tabular}

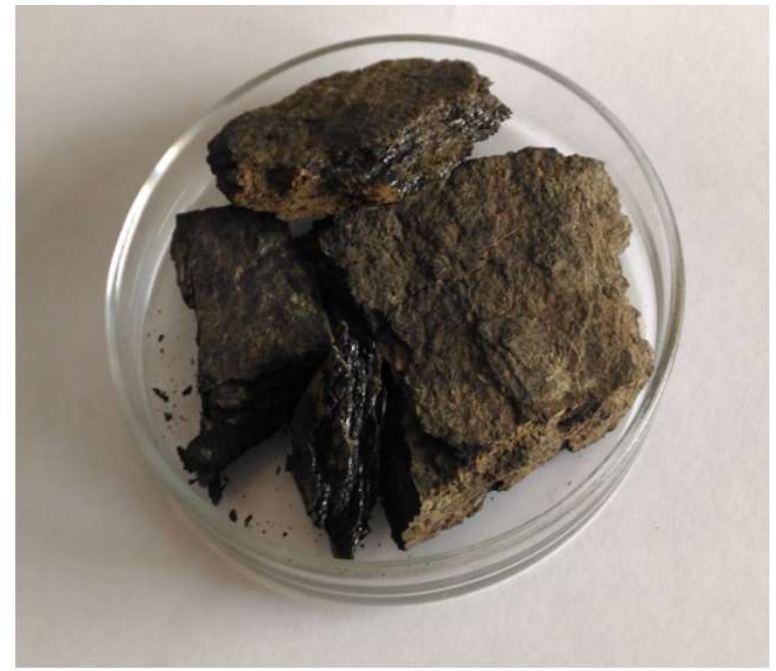

Fig. 1. The most abundant, tile-like modification of Barzas coals. 


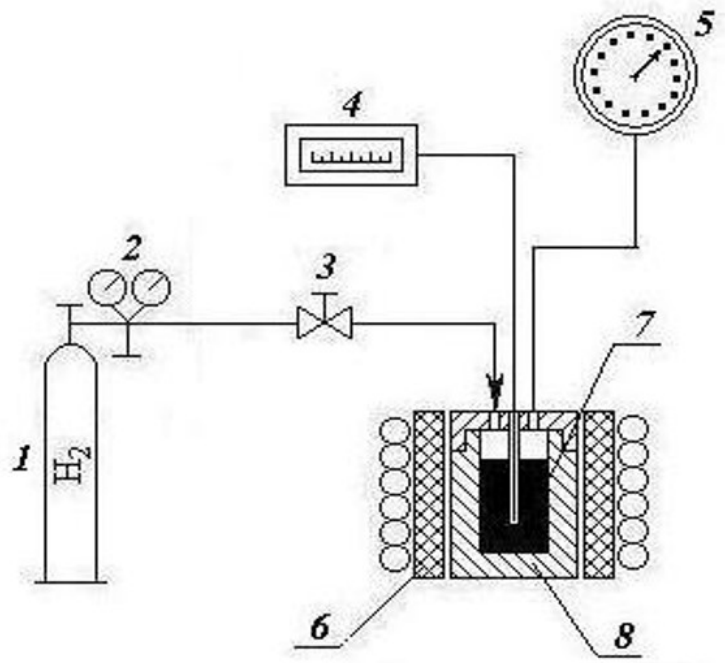

Fig. 2. Schematic view of a setup for coal hydro-liquefaction under high pressure: 1 - gas cylinder with hydrogen; 2 - gas 3edactor; 3 - valve; 4 - temperature regulator; 5 - manometer; 6 - electric furnace; 7 - coal sample; 8 - micro-autoclave.

The appearance of tile-like Barzas coal samples is shown in Fig. 1, and their basic characteristics are listed in Table 1. Proximate analysis of this coal was carried out using conventional methods [10], and its ultimate analysis, as well as elemental analyses of its thermal treatment products, were performed with a Flash 2000 elemental analyzer (Thermo Fisher Scientific, USA).

Several fractions of crushed and sieved Barzas coal particles sized of $\sim 1-3 \mathrm{~mm}$ were used for hydro-liquefaction experiments. Some of these coal fractions were modified with various transition metal-containing catalytic additives: 1) $1 \mathrm{wt} \% \mathrm{MoO}_{3}$ (by impregnation with aqueous solutions of ammonium dimolybdate, followed by drying of impregnates at $120^{\circ} \mathrm{C}$ for $4 \mathrm{~h}$ ); 2) 5 wt $\% \mathrm{Fe}_{2} \mathrm{O}_{3}$ (by impregnation with aqueous solutions of iron (III) nitrate nonahydrate, followed by drying of impregnates at $120^{\circ} \mathrm{C}$ for $4 \mathrm{~h}$ ) and 3) $11 \mathrm{wt} \%$ AlCoMo commercial hydrotreatment catalyst (by mixing of coal particles with the same size catalyst particles).

\subsection{Hydro-liquefaction}

Hydro-liquefaction of Barzas coal samples (with and without catalytic additives) were carried out using a specially constructed setup based on a microreactor-autoclave (of $\sim 20$ $\mathrm{cm}^{3}$ volume) capable to operate at high pressures and temperatures (Fig. 2). The reactor loaded with coal samples was pre-pumped with $\mathrm{H}_{2}$ up to $\mathrm{P} \sim 2.0 \mathrm{Mpa}$ and then heated up to $\mathrm{T} \sim 475^{\circ} \mathrm{C}$ and to the ending pressures in the range from 6.0 to $7.0 \mathrm{MPa}$; heating rate of coal samples in the reactor was of $10-12^{\circ} \mathrm{C} / \mathrm{min}$. The process temperature was controlled by a chromel-alumel thermocouple, and the pressure in the system was monitored by a manometer. The process duration at a given temperature was of 20 minutes, after which the reactor was cooled to room temperature.

Three main types of products are formed as a result of Barzas sapromixite thermal treatment in a hydrogen medium [9] : 1) gaseous products ; 2) resin-containing solid products and 3) small quantities (about 3-5 wt \%) of liquid products representing aqueous solutions of organic substances (the latter ones were sometimes emerged only after sapromixite heat treatment at $475^{\circ} \mathrm{C}$ ). The amount of gas formed after the reactor cooling 
was measured using a drum counter; all the solid and resin-like products remaining after the reaction were selecting, weighing and sending for IR and elemental analyses. Also, the concentrations of "coal liquids" (maltenes and asphaltenes) present in resin-containing solid products were determined by their sequential extraction in a Soxhlet apparatus [8, 9]. Preliminarily it was established that no maltenes and asphaltenes were contained in asreceived Barzas coal. For each experiment, a material balance of the solid, liquid and gaseous products formed was determined.

Yields of Barzas coal conversion products were calculated as follows:

$$
\begin{gathered}
\mathrm{Y}_{\mathrm{g}}=\left[\left(\mathrm{m}_{\mathrm{c}}-\mathrm{m}_{\mathrm{s}}-\mathrm{m}_{\mathrm{w}}\right) / \mathrm{m}_{\mathrm{c}}\right] \times 100 /\left[100-\mathrm{W}^{\mathrm{a}}-\mathrm{C}_{\mathrm{cat}}-\left(100-\mathrm{C}_{\mathrm{cat}}\right) \mathrm{A}^{\mathrm{d} / 100]}\right. \\
\mathrm{Y}_{\mathrm{w}}=\left[\mathrm{m}_{\mathrm{w}} / \mathrm{m}_{\mathrm{c}}\right] \times 100 /\left[100-\mathrm{W}^{\mathrm{a}}-\mathrm{C}_{\mathrm{cat}}-\left(100-\mathrm{C}_{\mathrm{cat}}\right) \mathrm{A}^{\mathrm{d} / 100}\right] \\
\mathrm{Y}_{\mathrm{m}}=\left[\mathrm{m}_{\mathrm{m}} / \mathrm{m}_{\mathrm{c}}\right] \times 100 /\left[100-\mathrm{W}^{\mathrm{a}}-\mathrm{C}_{\mathrm{cat}}-\left(100-\mathrm{C}_{\mathrm{cat}}\right) \mathrm{A}^{\mathrm{d} / 100]}\right. \\
\mathrm{Y}_{\mathrm{a}}=\left[\mathrm{m}_{\mathrm{a}} / \mathrm{m}_{\mathrm{c}}\right] \times 100 /\left[100-\mathrm{W}^{\mathrm{a}}-\mathrm{C}_{\mathrm{cat}}-\left(100-\mathrm{C}_{\mathrm{cat}}\right) \mathrm{A}^{\mathrm{d} / 100]}\right.
\end{gathered}
$$

where $Y_{g}, Y_{w}, Y_{m}$ and $Y a$ are the yields of gases, aqueous phase products, maltenes ( $n$ hexane 4oluble) and asphaltenes (benzene 4oluble but $n$-hexane insolubles), calculated on the dry ash-free (daf) basis, wt \%, respectively; $\mathrm{A}^{\mathrm{d}}$ and $\mathrm{W}^{\mathrm{a}}$ are the ash and moisture contents in feed coal, wt $\%$, respectively; $\mathrm{C}_{\text {cat }}$ is the concentration of a catalytic additive, wt $\% ; \mathrm{m}_{\mathrm{c}}, \mathrm{m}_{\mathrm{w}}, \mathrm{ms}, \mathrm{m}_{\mathrm{m}}$ and $\mathrm{m}_{\mathrm{a}}$ are the weights of feed coal, aqueous phase products, solid resin-containing products, maltenes and asphaltenes, $g$, respectively. The efficiency of coal liquefaction process (yield of "coal liquids") was calculated as a sum of the yields of maltenes and asphaltenes, wt \% (daf).

\subsection{FTIR analysis of hydroliquefaction products}

A Fourier transform IR (FTIR) spectroscopy method was used to study the functional composition of solid products obtained after hydroliquefaction of Barzas coal samples with and without catalytic additives; FTIR spectra of the samples studied were recorded with an Infralum FT-801 instrument (Lumex-Siberia, Russia) in the 500-4000 $\mathrm{cm}^{-1}$ spectral range using a $\mathrm{KBr}$ disk pressing technique.

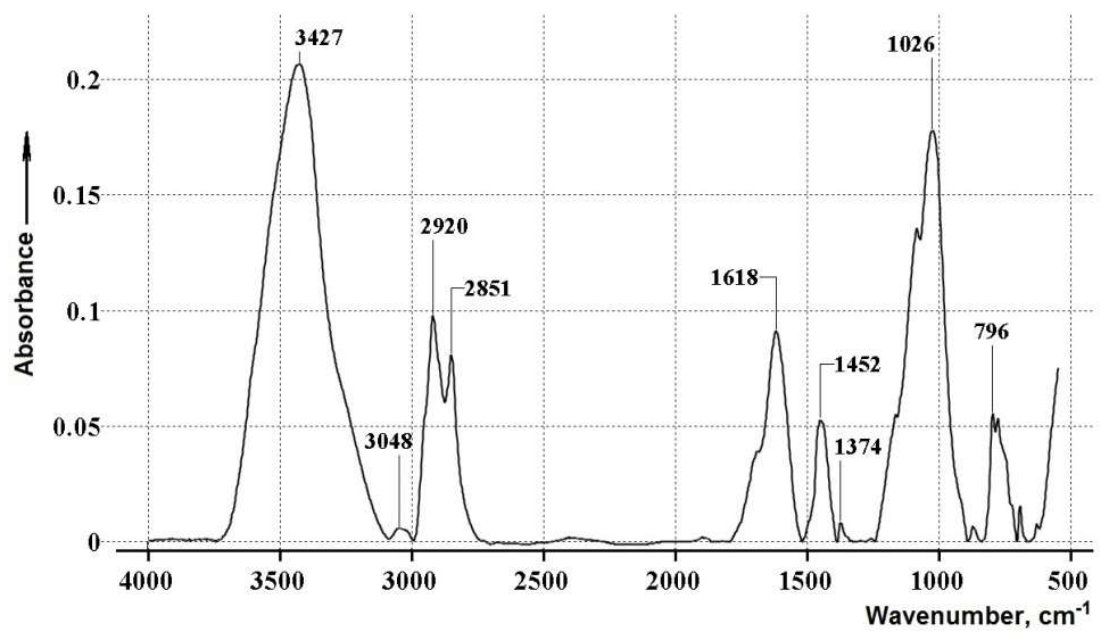

Fig. 3. A typical FTIR spectrum of as-received tile-like Barzas coal. 
Typical FTIR spectra of as-received tile-like Barzas coal and solid products of its hydro-liquefaction in the presence or absence of catalytic additives are presented in Figs. 35 .

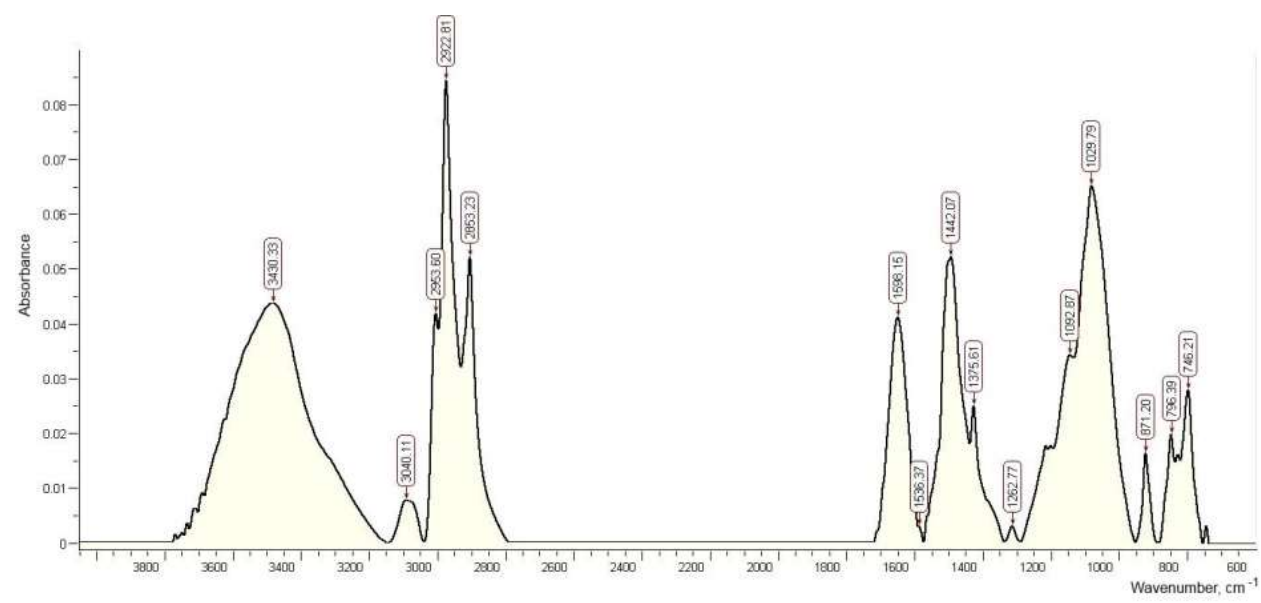

Fig. 4. A typical FTIR spectrum of catalytic additive-free Barzas coal after its thermal treatment in a hydrogen medium at $475^{\circ} \mathrm{C}$.

According to literature data on the IR spectra of various coals [11, 12], the main groups of Barzas sapromixite sample IR absorption bands are manifested in the following frequency ranges : $3700-3200 \mathrm{~cm}^{-1}$ with a maximum at $\sim 3480 \mathrm{~cm}^{-1}-$ stretching vibrations of hydrogen-bonded $\mathrm{OH}$ groups ; 3080-3020 $\mathrm{cm}^{-1}$ - stretching vibrations of aromatic $\mathrm{C}-\mathrm{H}$ groups; 2920-2960 $\mathrm{cm}^{-1}$ with a maximum about $2947 \mathrm{~cm}^{-1}$ - stretching vibrations of methylene $>\mathrm{CH}_{2}$ groups and asymmetric stretching vibrations of $\mathrm{CH}_{3}$ groups; 2860-2880 $\mathrm{cm}^{-1}$ - symmetric stretching vibrations of $\mathrm{CH}_{3}$ groups; an intensive absorption band at $1600 \mathrm{~cm}^{-1}-$ stretching vibrations of aromatic $\mathrm{C}=\mathrm{C}$ groups, which is partially overlapping with an absorption band of water deformation (bending) vibrations $\left(\delta_{\mathrm{H}-\mathrm{O}-\mathrm{H}}\right)$, manifested in the $\sim 1630-1650 \mathrm{~cm}^{-1}$ region ; an absorption band at $\sim 1700 \mathrm{~cm}^{-1}-$ stretching vibrations of carbonyl $\mathrm{C}=\mathrm{O}$ groups; absorption bands in the $1450-1430 \mathrm{~cm}^{-1}$ - bending vibrations of $\mathrm{CH}_{2}$ groups and asymmetric deformation vibrations of $\mathrm{CH}_{3}$ groups; an absorption band at $1380 \mathrm{~cm}^{-1}$ - symmetric deformation vibrations of $\mathrm{CH}_{3}$ groups.

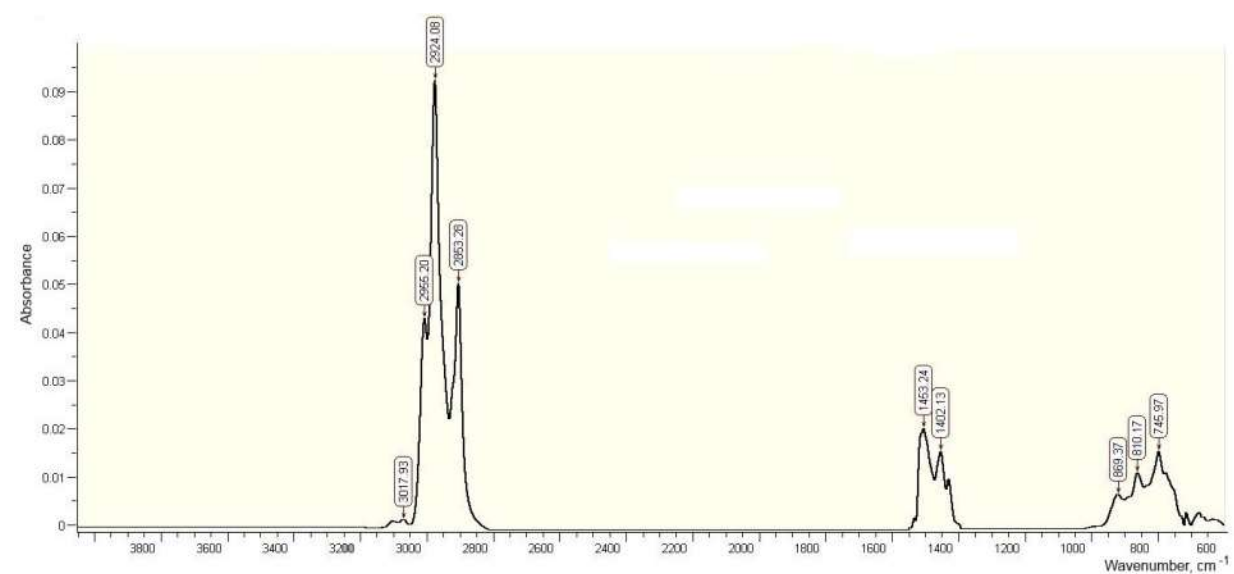

Fig. 5. A typical FTIR spectrum of Barzas coal modified with 11 wt.\% AlCoMo catalyst and then thermally treated in a hydrogen medium at $475^{\circ} \mathrm{C}$. 
Besides that, the following absorption bands are also observed in these spectra : an absorption band in the $1200-1100 \mathrm{~cm}^{-1}$ region - stretching vibrations of C-O-H groups.

A group of absorption bands in the $1080-1020 \mathrm{~cm}^{-1}$ interval with a maximum at $\sim 1050$ $\mathrm{cm}^{-1}$ - stretching vibrations of bridging ether C-O-C groups; a group of absorption bands in the $700-900 \mathrm{~cm}^{-1}$ range that are associated with out-of-plane vibrations of aromatic ring C$\mathrm{H}$ bondings.

A semi-quantitative assessment of changes occurring in the solid samples of Barzas coals after their hydro-liquefaction in the absence and in the presence of catalytic additives was made from variations in relative intensities of the absorption bands belonging to alkyl groups $\left(\mathrm{CH}_{3}\right.$ and $\mathrm{CH}_{2}$ groups), defined as the areas of infrared absorption bands in the 2800-2970 $\mathrm{cm}^{-1}$ range, normalized to the total area of all the absorption bands in the FTIR spectrum of the sample studied, i. e., from $\left(\mathrm{A}_{\mathrm{CH}_{3}}+\mathrm{A}_{\mathrm{CH}_{2}}\right) / \Sigma \mathrm{A}_{\mathrm{n}}$ ratios.

\section{Results and Discussion}

Analysis of FTIR spectra presented in Fig. 3-5 shows that heat treatment of Barzas coals under pressure in a hydrogen atmosphere leads to a sharp decrease in the intensity of IR absorption bands related with oxygen-containing groups, especially the absorption bands of OH groups $\left(\sim 3430 \mathrm{~cm}^{-1}\right), \mathrm{C}=\mathrm{O}$ groups $\left(\sim 1700 \mathrm{~cm}^{-1}\right)$ and $\mathrm{C}-\mathrm{O}-\mathrm{C} / \mathrm{C}-\mathrm{O}-\mathrm{H}$ groups $(1000-$ $1100 \mathrm{~cm}-1)$. In addition, the fall in intensity of IR absorption bands associated with aromatic structures $\left(\sim 3030 \mathrm{~cm}^{-1}\right.$ and $\left.\sim 1600 \mathrm{~cm}^{-1}\right)$ is also observed. On the other hand, the IR absorption bands intensities of alkyl groups (peaks at 1800-1970 $\mathrm{cm}^{-1}, \sim 1450 \mathrm{~cm}^{-1}$ and $\sim 1380 \mathrm{~cm}^{-1}$ ) markedly increase. These changes point to the O-containing functional groups removal and the occurrence of coal hydrogenation reactions. In the presence of catalytic additives, these processes become much more intensive; thus, solid products of Barzas coal hydro-liquefaction obtained in the presence of an AlCoMo catalyst additive practically do not contain any oxygen-containing and aromatic structures (see Fig. 5).

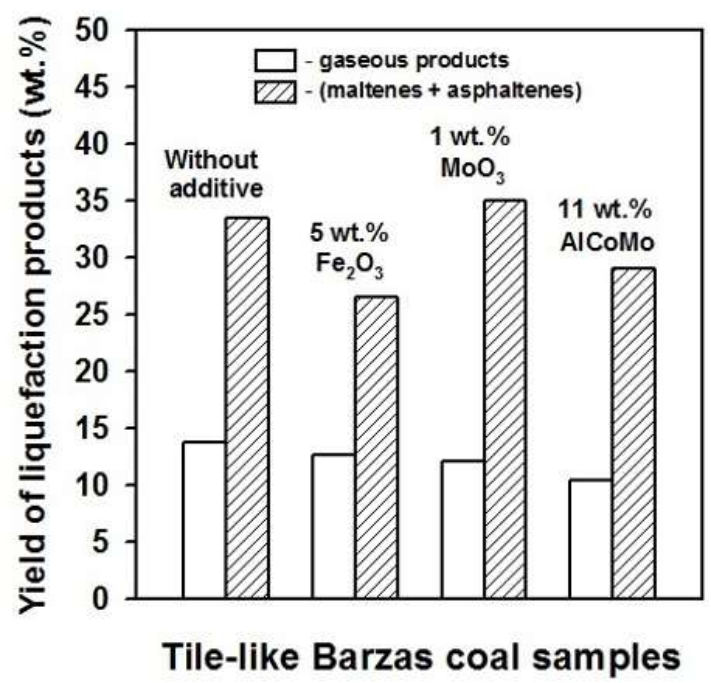

Fig. 6. Effects of catalytic additives on the yields of Barzas coal hydro-liquefaction products. 


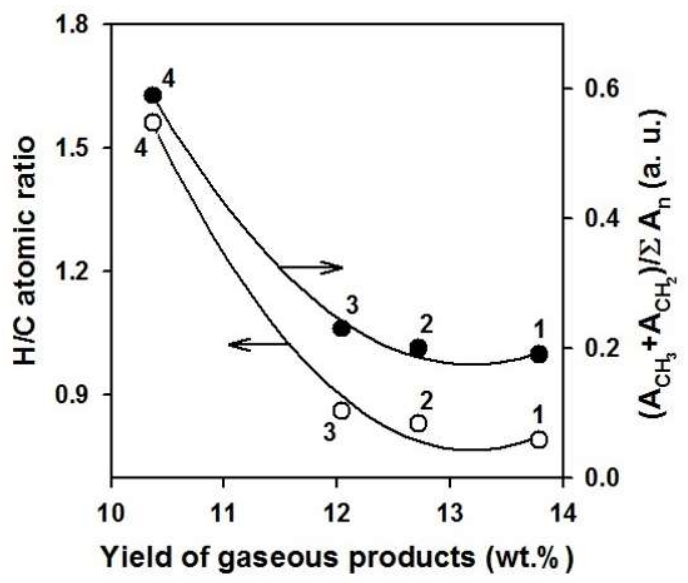

Fig. 7. Dependences of $\mathrm{H} / \mathrm{C}$ atomic ratios and relative IR absorption band intensities of alkyl groups in solid products of Barzas coal hydro-liquefaction on the yields of gaseous products: coal samples without catalytic additive (1), with 5 wt. $\% \mathrm{Fe}_{2} \mathrm{O}_{3}$ (2), with 1 wt.\% $\mathrm{MoO}_{3}$ (3) and with 11 wt.\% AlCoMo catalyst (4).

Effects of catalytic additives on the yields of "coal liquids" during Barzas coal hydroliquefaction are plotted as hystograms in Fig. 6. As it can be seen from this figure, in the presence of catalytic additives, the yield of gaseous products somewhat decreases, and, besides that, in case of the Mo-containing additive, the yield of liquid (resin-like) products slightly increases, as compared to that for a coal sample without catalyst. Maximal yields of "coal liquids" (maltenes + asphaltenes) ( $35 \mathrm{wt} . \%$, daf basis) were obtained during the heat treatment of sapromixites in the presence of $\sim 1 \mathrm{wt} . \% \mathrm{MoO}_{3}$. Figure 7 demonstrates relationships between yields of gaseous products and $\mathrm{H} / \mathrm{C}$ atomic ratios and also relative IR absorption band intensities of alkyl groups in solid products of Barzas coal hydroliquefaction in the presence or absence of catalytic additives. The data presented here clearly indicate a close relationship between the amount of hydrogen-rich structures in resin-like products of Barzas coal transformations and gas formation processes during its thermal treatment: the higher the gas yield during coal hydro-liquefaction, the lower the $\mathrm{H} / \mathrm{C}$ atomic ratio and the lower the concentration of alkyl groups in resin-like solid products of coal transformations. Similar regularities were also observed in the studies of temperature dependences of Barzas coal thermal decompositions in various media $[8,9]$.

Authors would like to express their deep gratitude to the co-workres of Kemerovo Regional Center for Collective Use of the SB RAS (KemCCU) for technical help in conducting IR spectroscopic, elemental, and chromatographic analyses of Barzas coals samples and their conversion products. Also, the authors are very grateful to MSc. D.M. Kosarev (Department of Heat Power Engineering, Kuzbass State Technical University, Kemerovo) for performing some proximate analyses of as-received Barzas coal.

\section{References}

1. C. Burgess Clifford, C. Song, Advances in clean hydrocarbon fuel processing (Woodhead Publ. Ltd., New Delhi, 2011)

2. S. Vasireddy, B. Morreale, A. Cugini, C. Song, J.J. Spivey, Energy \& Environ. Sci. 4, 311 (2011)

3. A.S. Maloletnev, M.Ya. Shpirt, Russ. J. Gen. Chem., 79, 2499 (2009) 
4. M. Hook, K. Aleklett, Int. J. Energy Res., 34, 848 (2010)

5. I. Petrov, B. Tryasunov, E3S Web of Conferences, 21, 01004 (2017)

6. Y.F. Patrakov, S.V. Denisov, Fuel, 70, 267 (1991)

7. V.I. Sharypov, B.N. Kuznetsov, N.G. Beregovtsova, A.N. Startsev, V.N. Parmon, Fuel 85, 918 (2006)

8. I. Petrov, K. Ushakov, A. Bogomolov, B. Tryasunov, E3S Web of Conferences, 41, 01037 (2018)

9. I.Y. Petrov, K.Y. Ushakov, A.R. Bogomolov, B.G. Tryasunov, Int. J. Eng. \& Technol., 7, $161(2018)$

10. J.G. Speight, Handbook of Coal Analysis, $2^{\text {nd }}$ ed. (Wiley, Hoboken, NJ, 2015)

11. P.R. Solomon, In: Advances in coal spectroscopy (Springer Science, Business Media, New York, 1992)

12. P.R. Solomon, D.G. Hamblen, Chemistry of coal conversion (Springer Science, Springer Media, LLC, New York, 1985) 